\title{
Performance of the ATLAS Transition Radiation Tracker
}




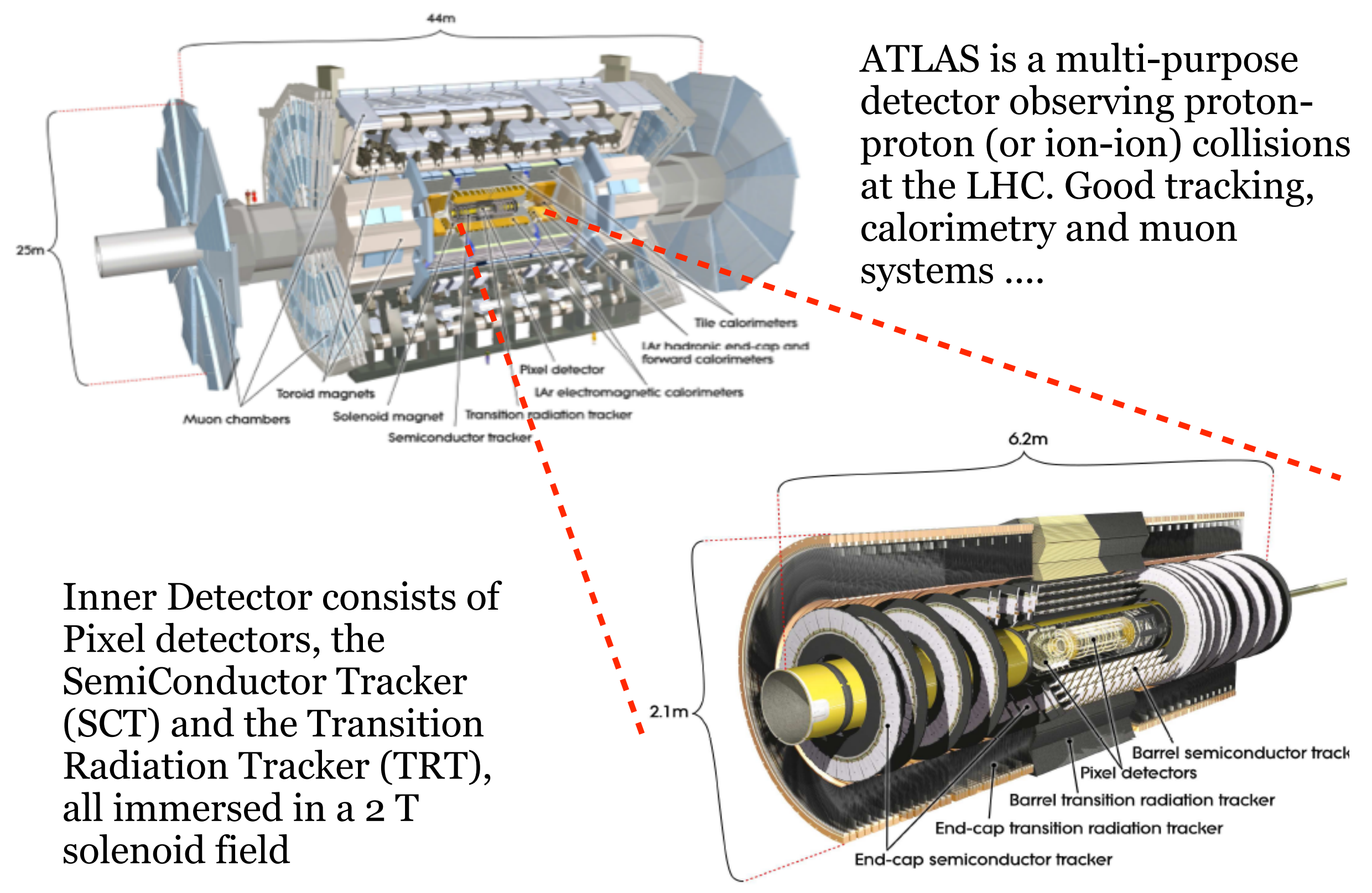

ATLAS is a multi-purpose detector observing protonproton (or ion-ion) collisions systems ....

Inner Detector consists of Pixel detectors, the SemiConductor Tracker (SCT) and the Transition Radiation Tracker (TRT), all immersed in a $2 \mathrm{~T}$ solenoid field 


\section{The TRT}

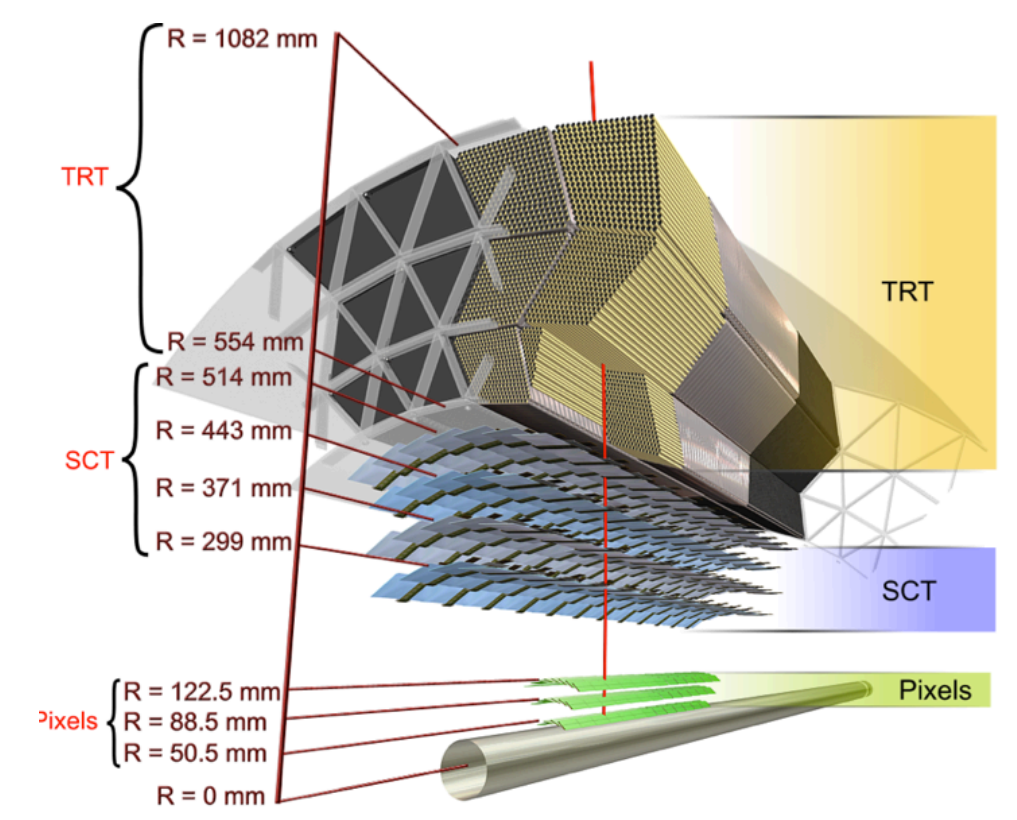

\section{TRT Barrel}

- 3 x 32 (phi) modules

- $1.44 \mathrm{~m}$ straws parallel to beam axis

- Wires electrically split in middle to reduce occupancy

- Each end read out separately

- First 9/73 layers of straws active only for $312 \mathrm{~mm}$ on outer ends

- 105,000 readout channels

- Irregularly spaced polypropylene fiber radiators in between straws

\section{TRT Endcaps}

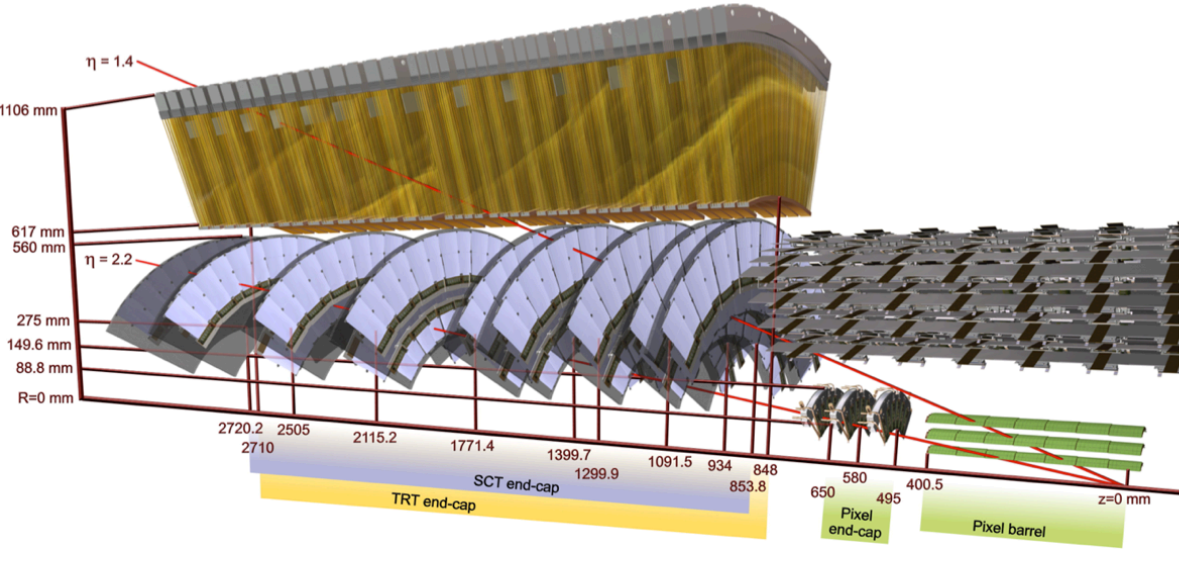

- At smaller z, 6 wheels with 16 layers of straws x 32 (phi)

- At larger z, 8 wheels with 8 layers of straws x 32 (phi)

- Larger spacing at large z

- $39 \mathrm{~cm}$ long radial straws

- 123,000 readout channels per endcap

- Plastic radiator foils between each of 160 planes 


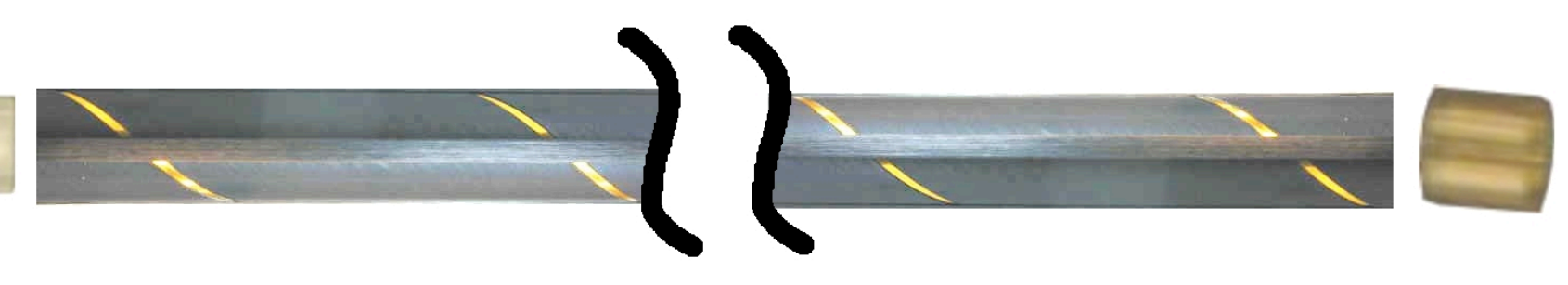

- Diameter of straw $=4 \mathrm{~mm}$

- Straw wall is carbon kapton with carbon fiber supports

- Straw wall thickness $=70$ microns

- Kept at -1530 volts

- Wire is gold-plated tungsten

- Diameter $=31$ microns

- Kept at ground

- Gas circulating inside straw: $70 \% \mathrm{Xe}, 27 \% \mathrm{CO}_{2}, 3 \% \mathrm{O}_{2}$

- Xenon to absorb transition radiation 


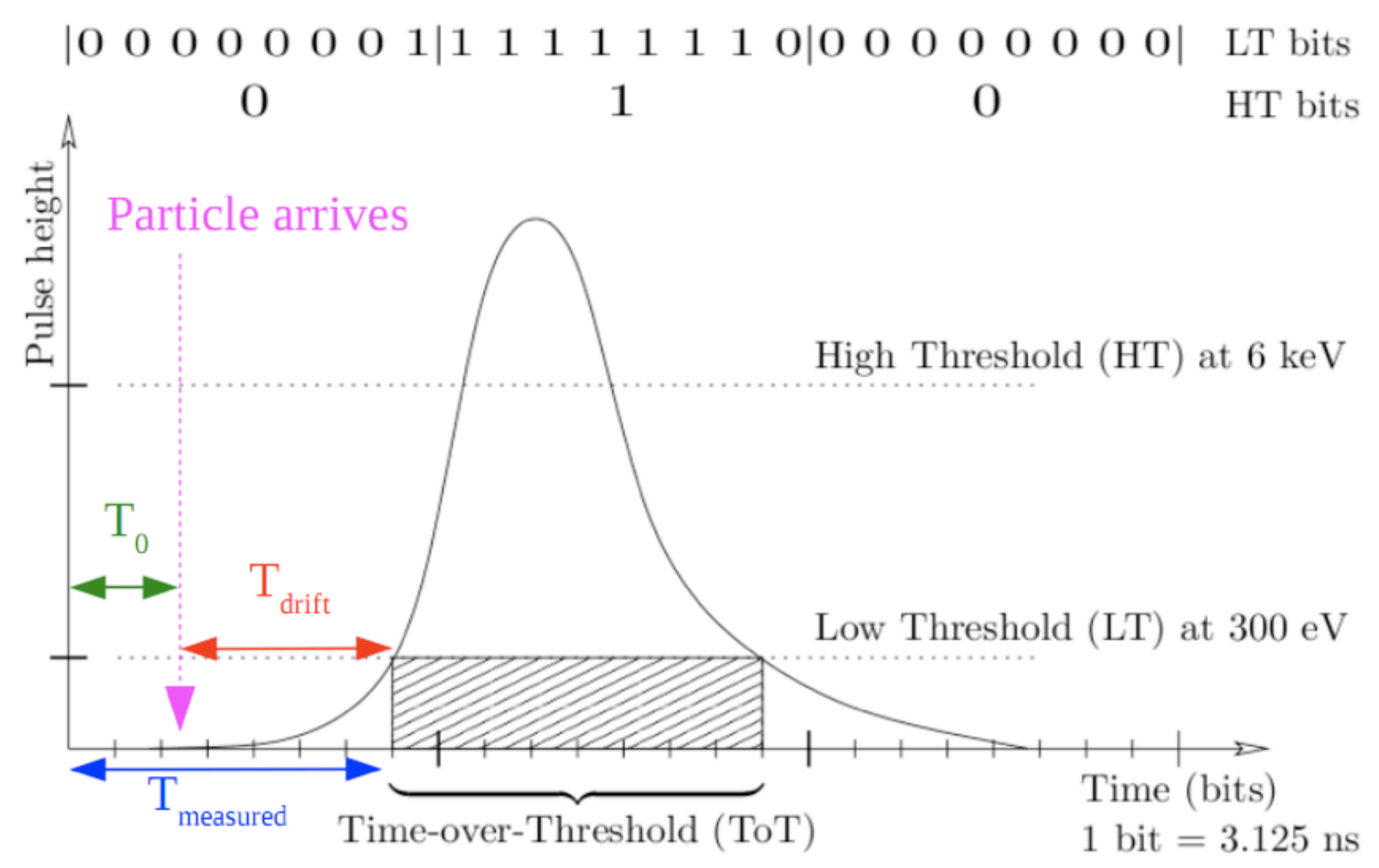

- Each straw signal read out over $75 \mathrm{~ns}=3$ nominal bunch crossings

- The low threshold (tracking) signal is digitized into 24 bins of $3.125 \mathrm{~ns}$

- Use first 0->1 edge transition for tracking

- The high threshold (TR) signal is digitized 3 times (every $25 \mathrm{ns)}$ 


\section{In-time pileup}

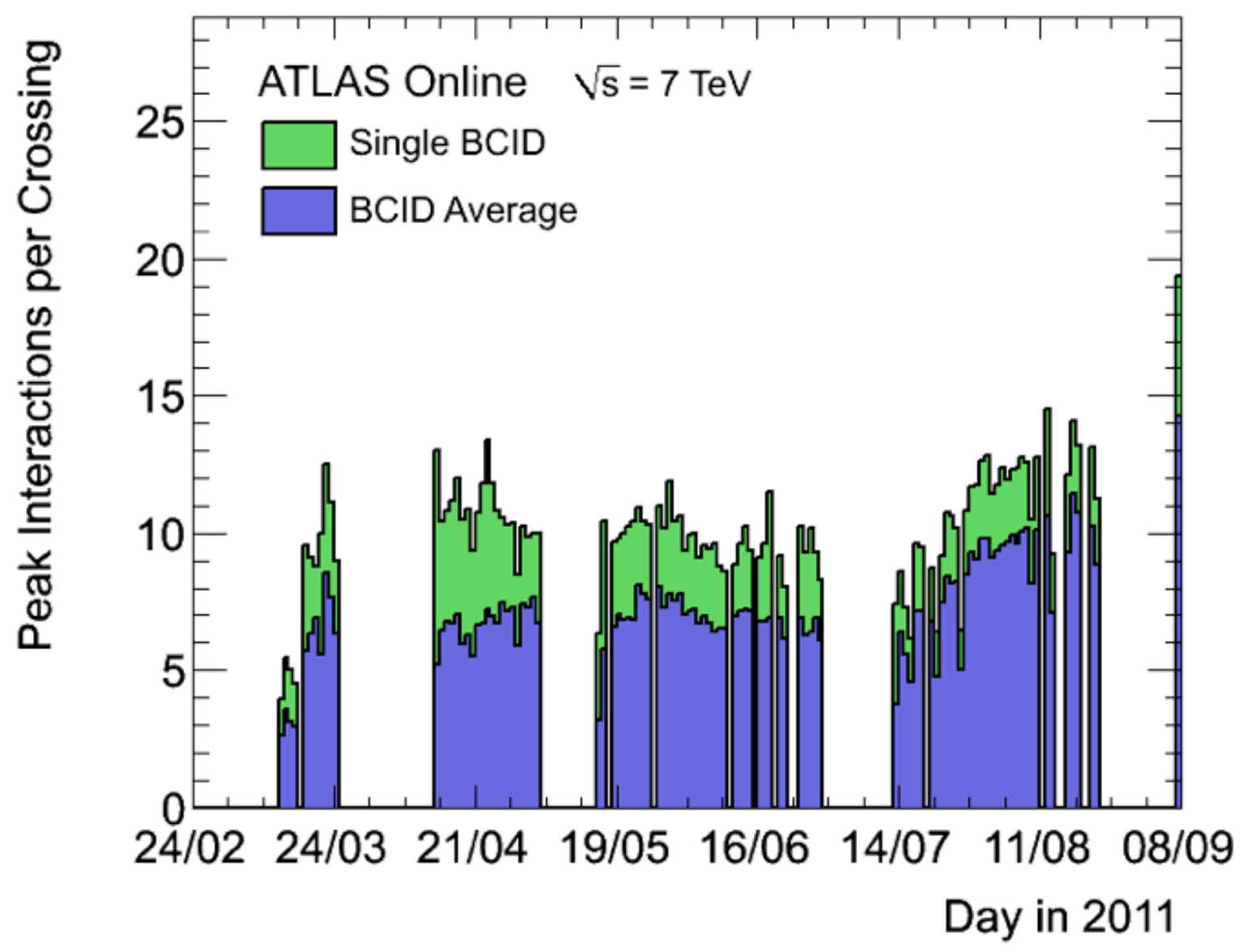

After recent LHC improvements, close to 15 events per bunch crossing... on average! 


\section{Out-of-time pileup?}

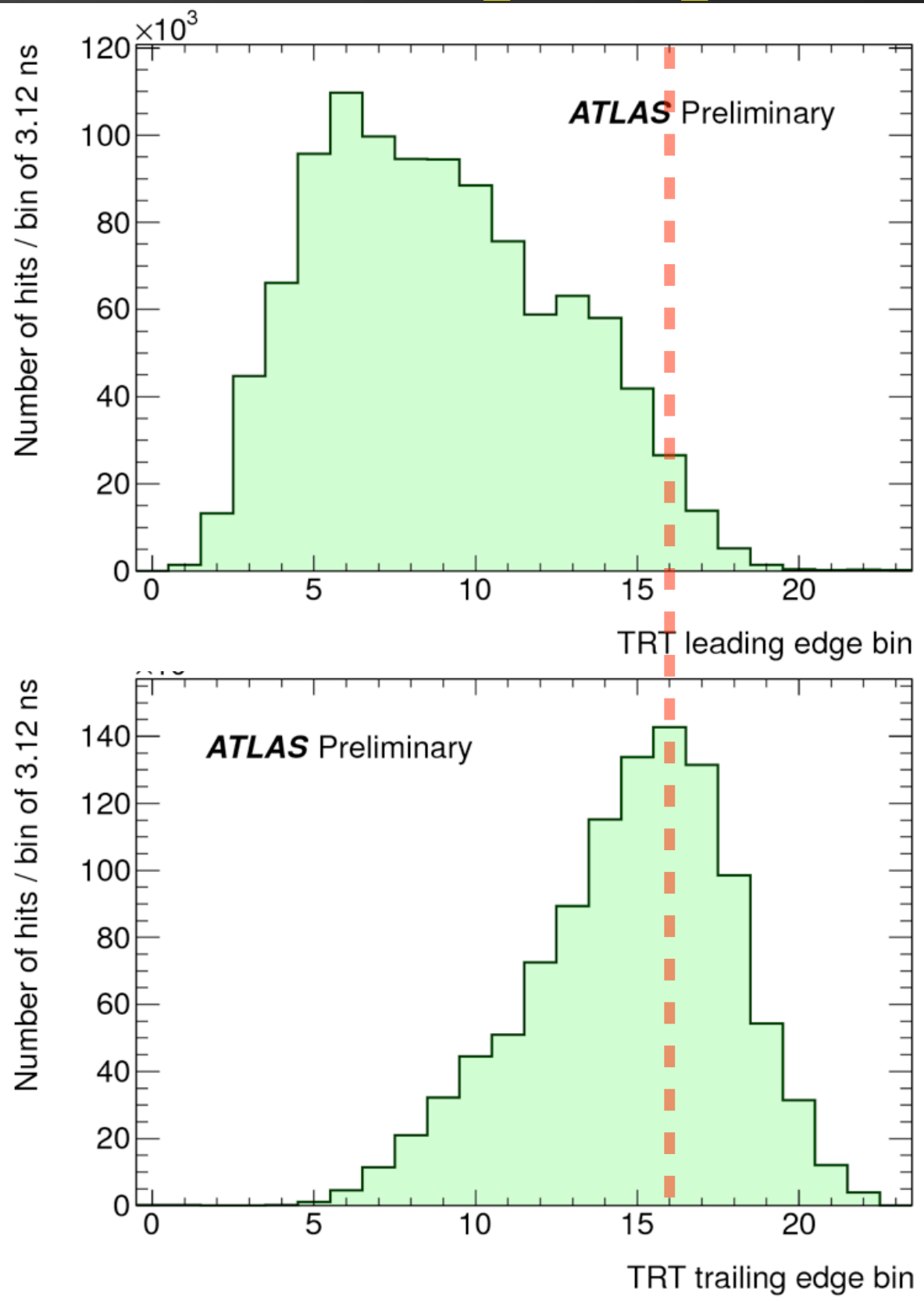

LHC currently running with 50 ns bunch spacing - easily handled by cutting on leading edges that are too large, and requiring valid $0->1$ transition. Next year, may see 25 ns spacing! 


\section{ATLAS} LEXPERIMENT
Run Number: 154817, Event Number: 968871 Date: 2010-05-09 09:41:40 CEST

$M_{\mathrm{ee}}=89 \mathrm{GeV}$

Z $\rightarrow$ ee candidate in $7 \mathrm{TeV}$ collisions

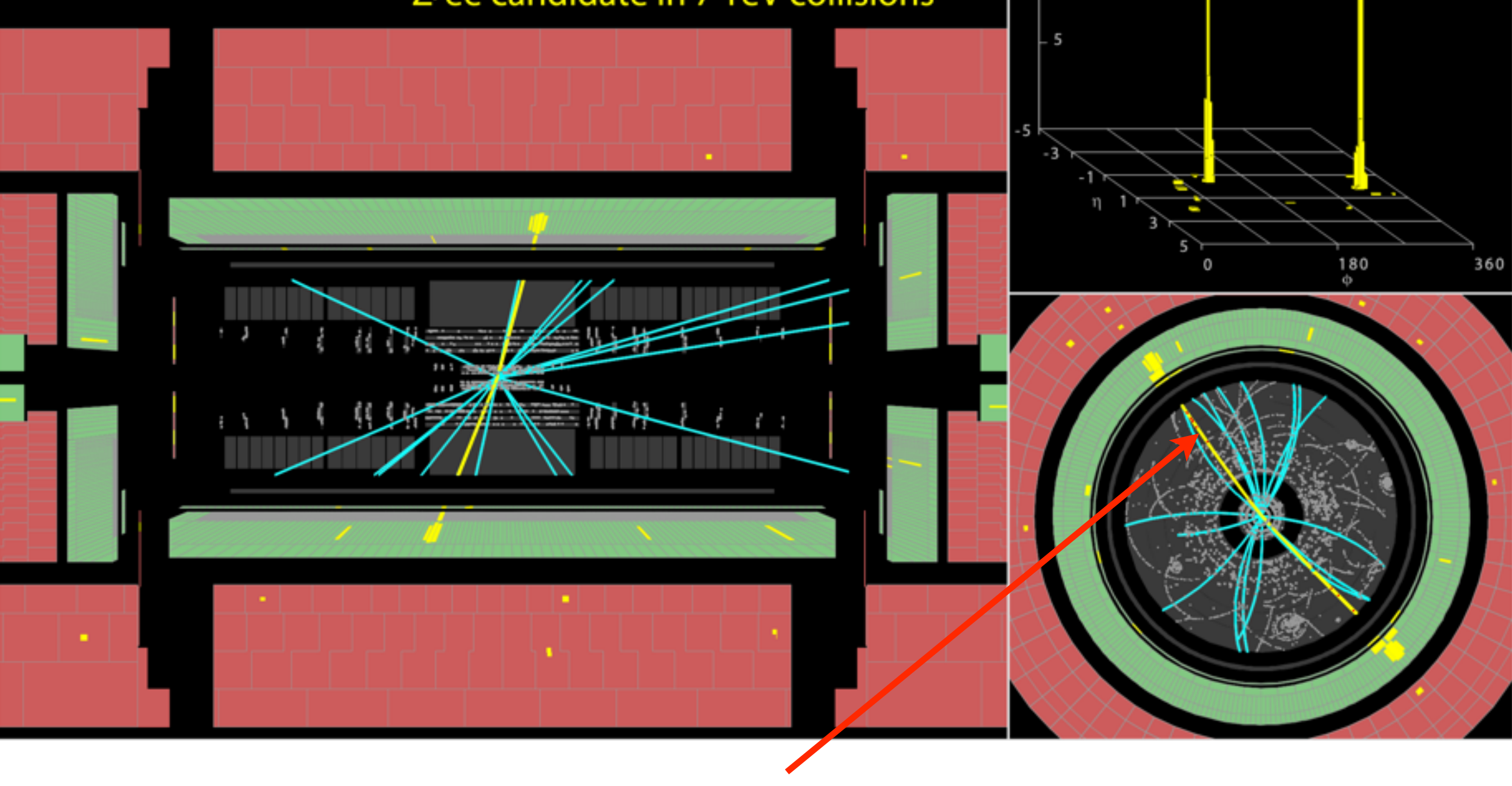

TRT High Threshold hits on track 


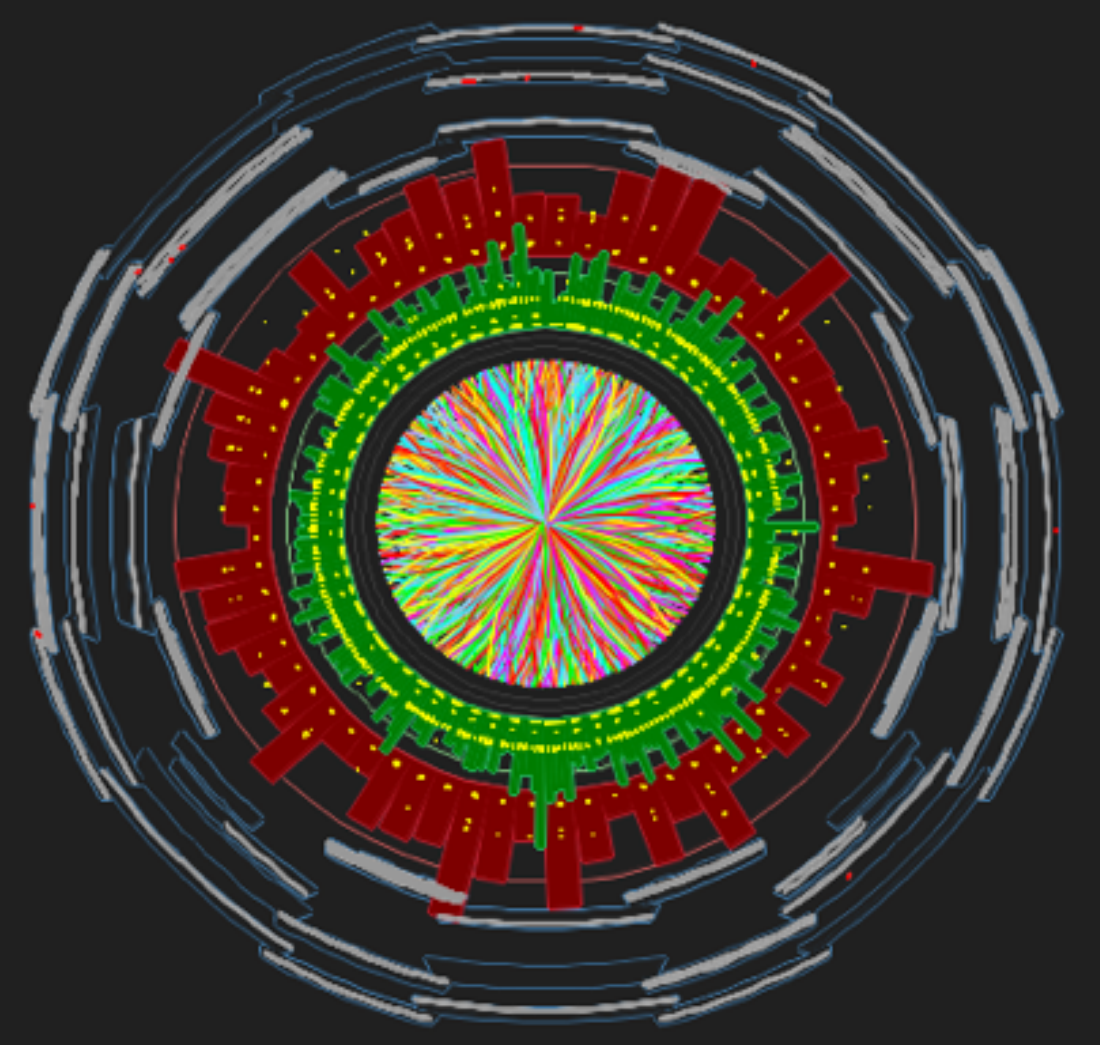

A Run Number: 168665, Event Number: 57983 道EXPERIMENT Date: 2010-11-08 11:29:31 CET

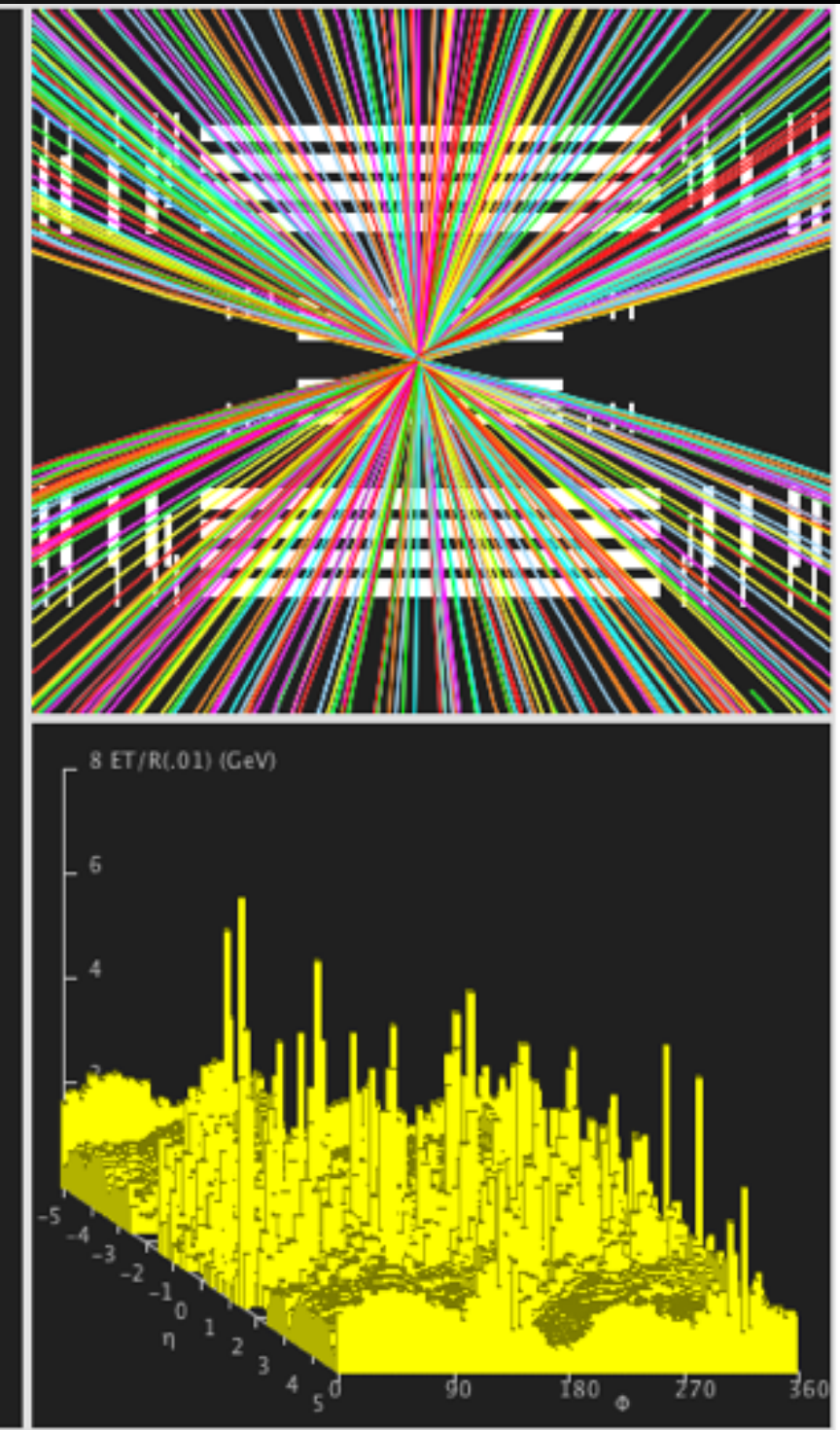

1115 reconstructed tracks with $\mathrm{p}_{\mathrm{T}}>1 \mathrm{GeV}$ 

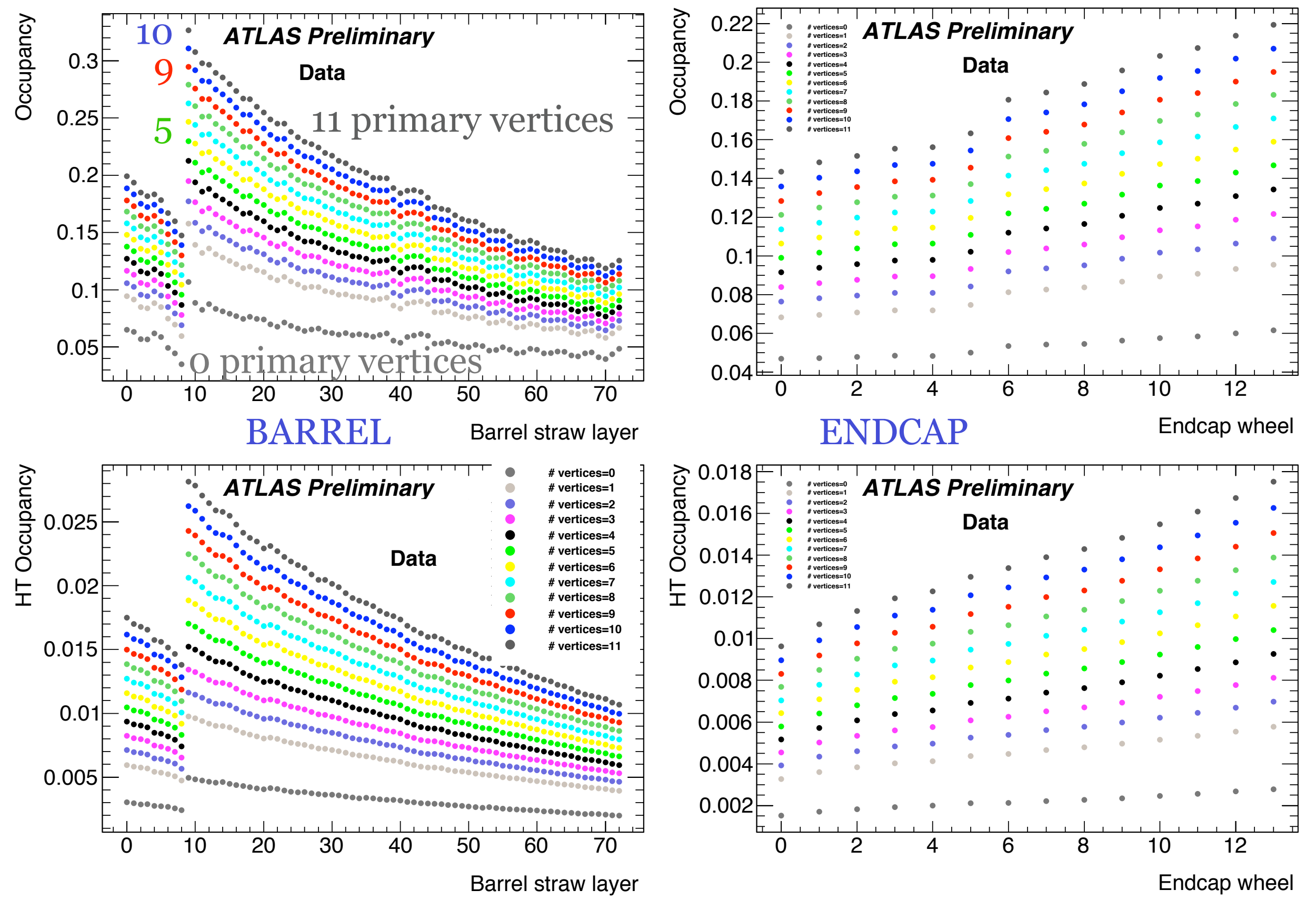
Look at how the occupancy changes as an additional reconstructed primary vertex is found in the event. Should be a measure of the additional in-time occupancy from every minimum bias interaction. 


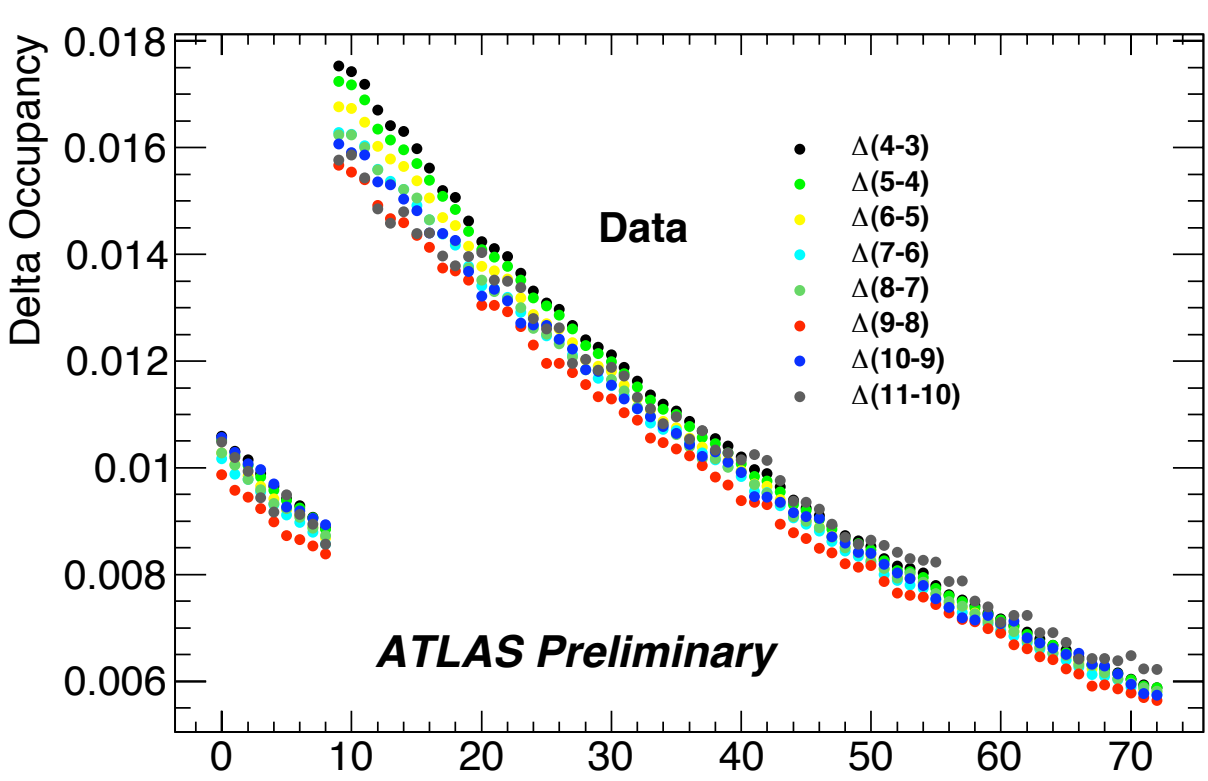

Barrel straw layer

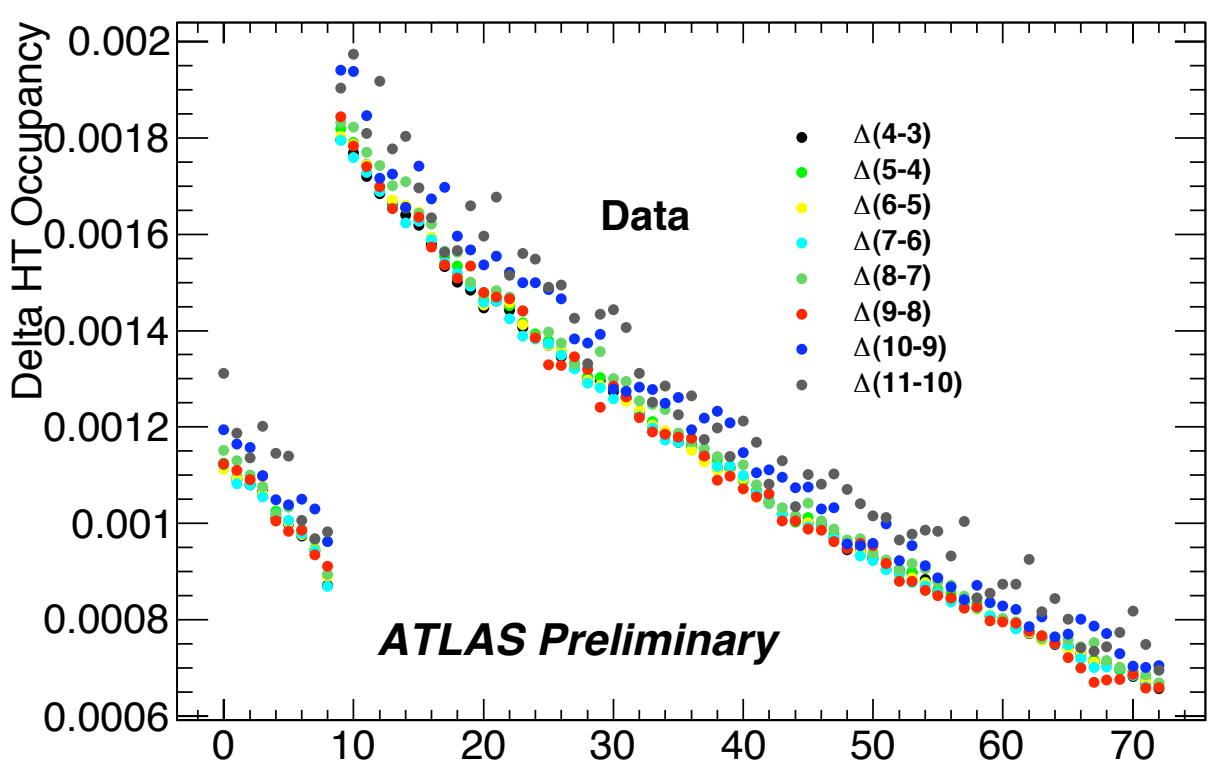

Barrel straw layer
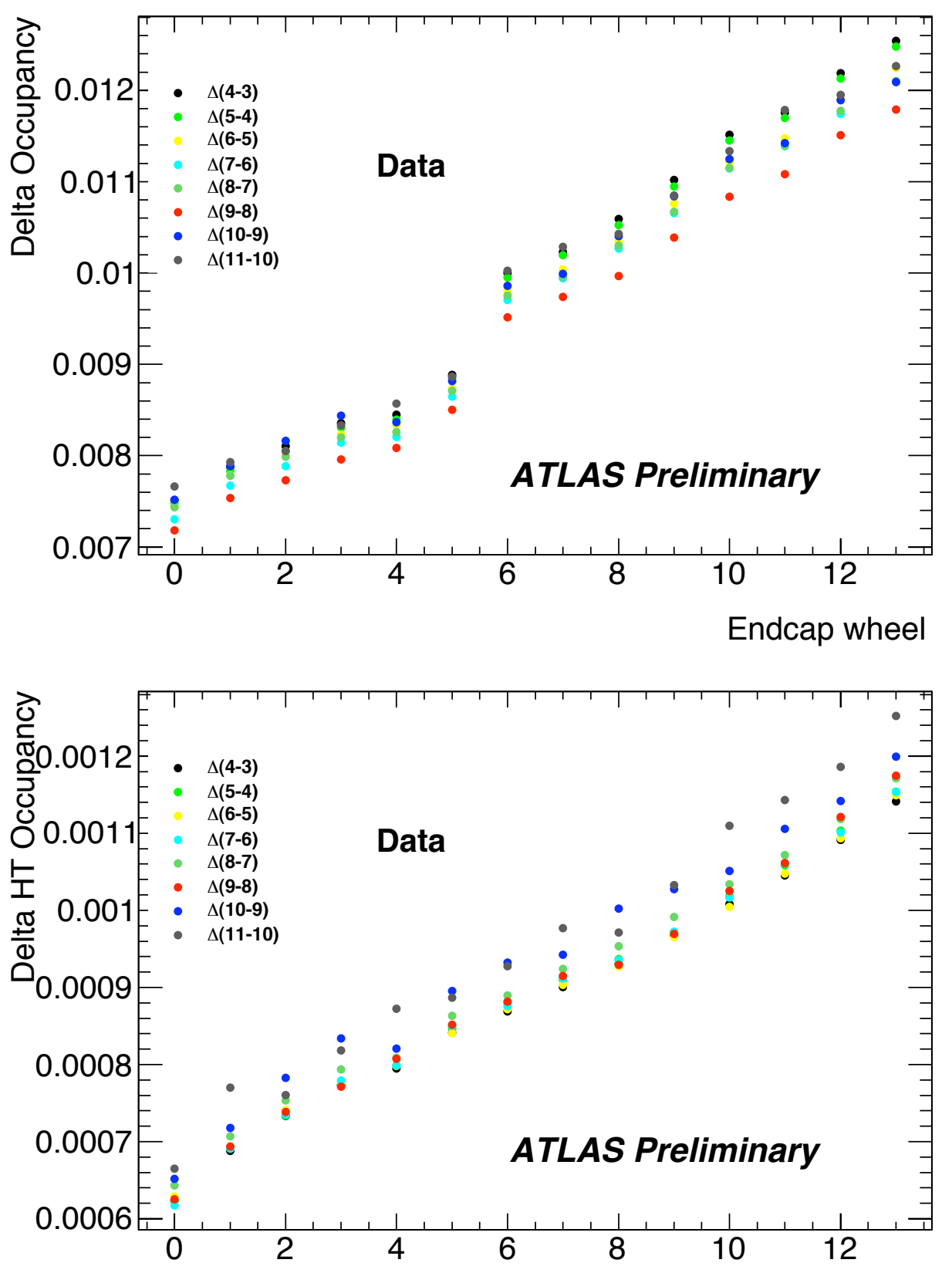

Endcap wheel 


\section{Using delta occupancy}

- Do we have lots of overlapping low-energy particles contributing to occupancy at high $\mathrm{N}$ interactions?

- $\mathrm{P}($ hit $)=\mathrm{x}$

- $\mathrm{P}($ nohit $)=1-\mathrm{x}$

- $\mathrm{P}($ nohit $)$ for $\mathrm{N}$ interactions $=(1-\mathrm{X})^{\mathrm{N}}$

- $\mathrm{P}($ at least one hit $)=1-\mathrm{P}($ nohit $)=1-(1-\mathrm{x})^{\mathrm{N}}$

- This probability can be compared to the measured occupancy in data. Look at occupancy for $\mathrm{N}+1$ interactions and subtract occupancy at 1 interaction (this removes the extra dependency on the hard scattering physics process) 

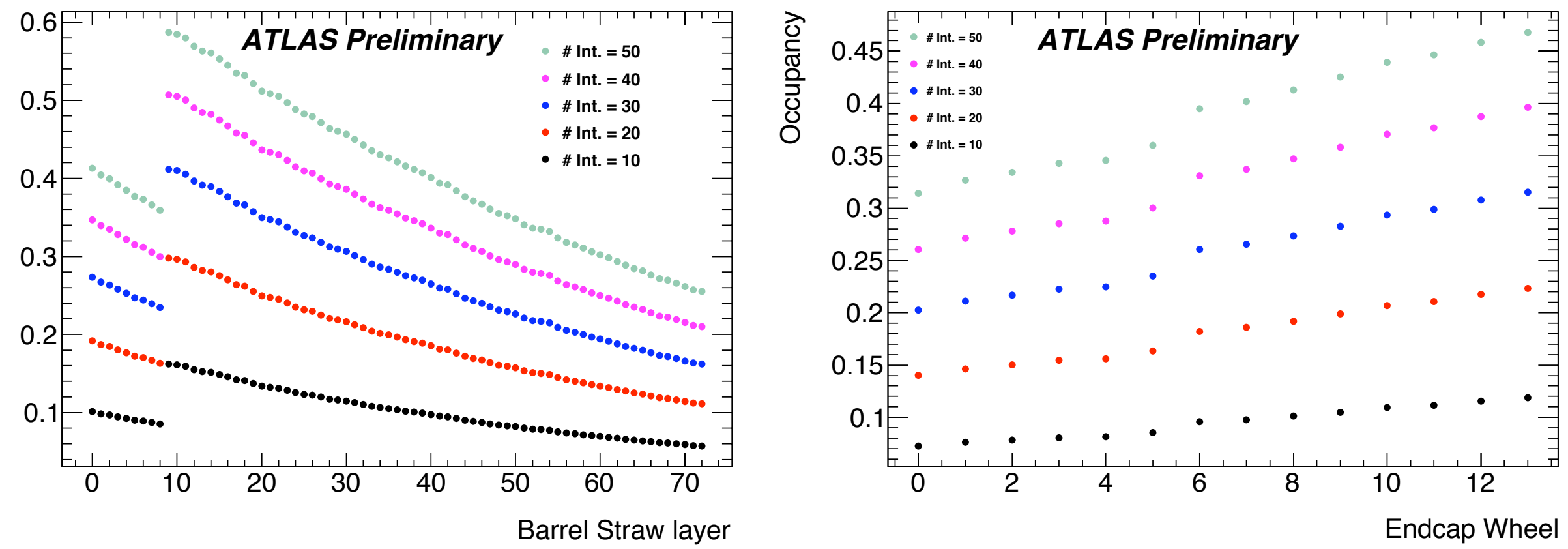

\begin{tabular}{|c|c|c|c|c|c|}
\hline Region & Type & $\mathrm{N}=11$ occupancy & $\mathrm{N}=1$ occupancy & Observation & Prediction for $\mathrm{N}=10$ \\
\hline Barrel Layer 10 & LT & 33 & 16 & 17 & 16 \\
Barrel Layer 10 & HT & 2.8 & 1.0 & 1.8 & 1.8 \\
Barrel Layer 72 & LT & 13 & 7 & 6 & 6 \\
Barrel Layer 72 & HT & 1.1 & 0.4 & 0.7 & 0.7 \\
Endcap Layer 0 & LT & 13 & 6 & 7 & 7 \\
Endcap Layer 0 & HT & 0.9 & 0.3 & 0.6 & 0.6 \\
Endcap Layer 159 & LT & 20 & 9 & 11 & 11 \\
Endcap Layer 159 & HT & 1.8 & 0.6 & 1.2 & 1.2 \\
\hline
\end{tabular}




\section{Residuals Maps}

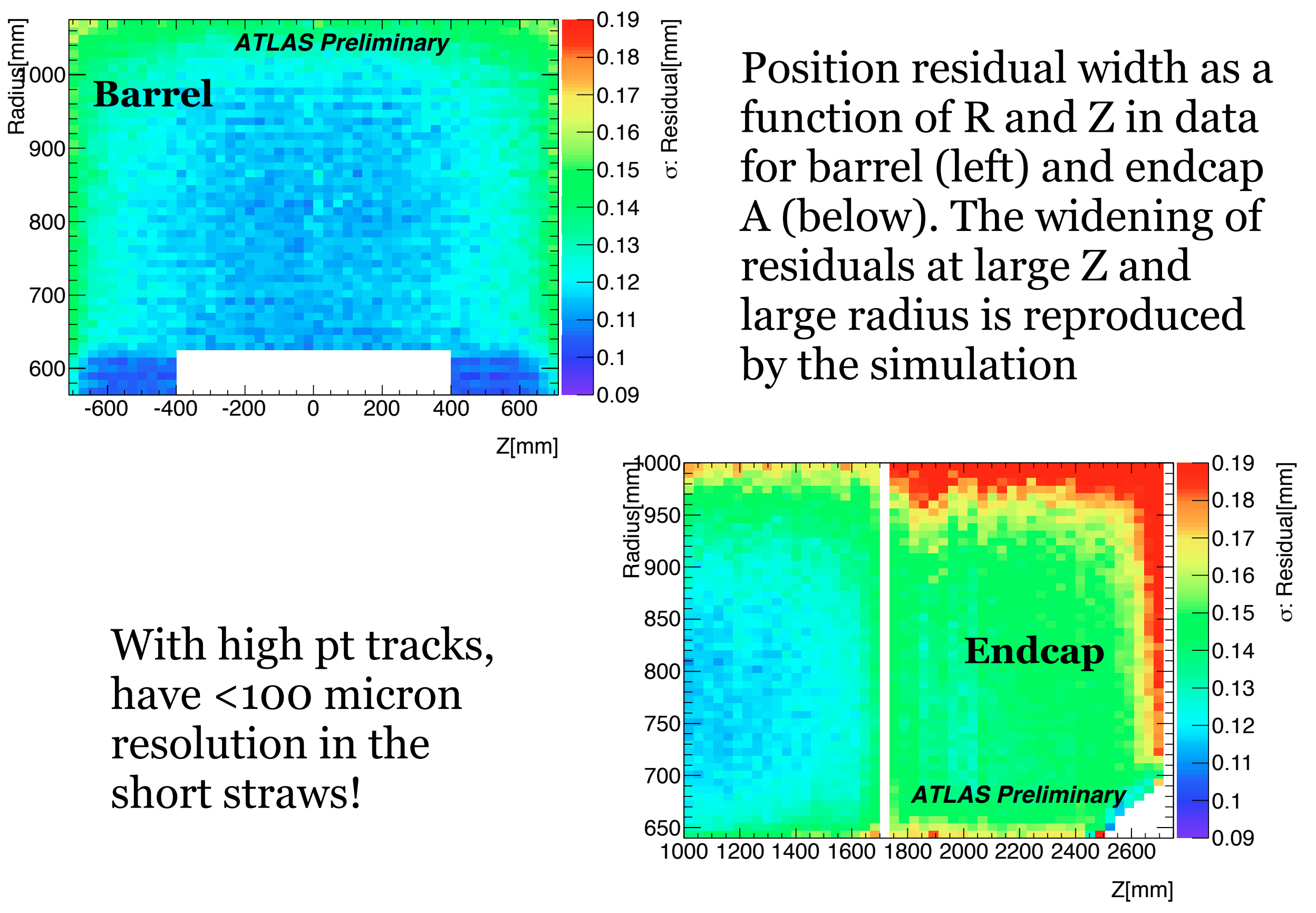




\section{Importance of alignment}
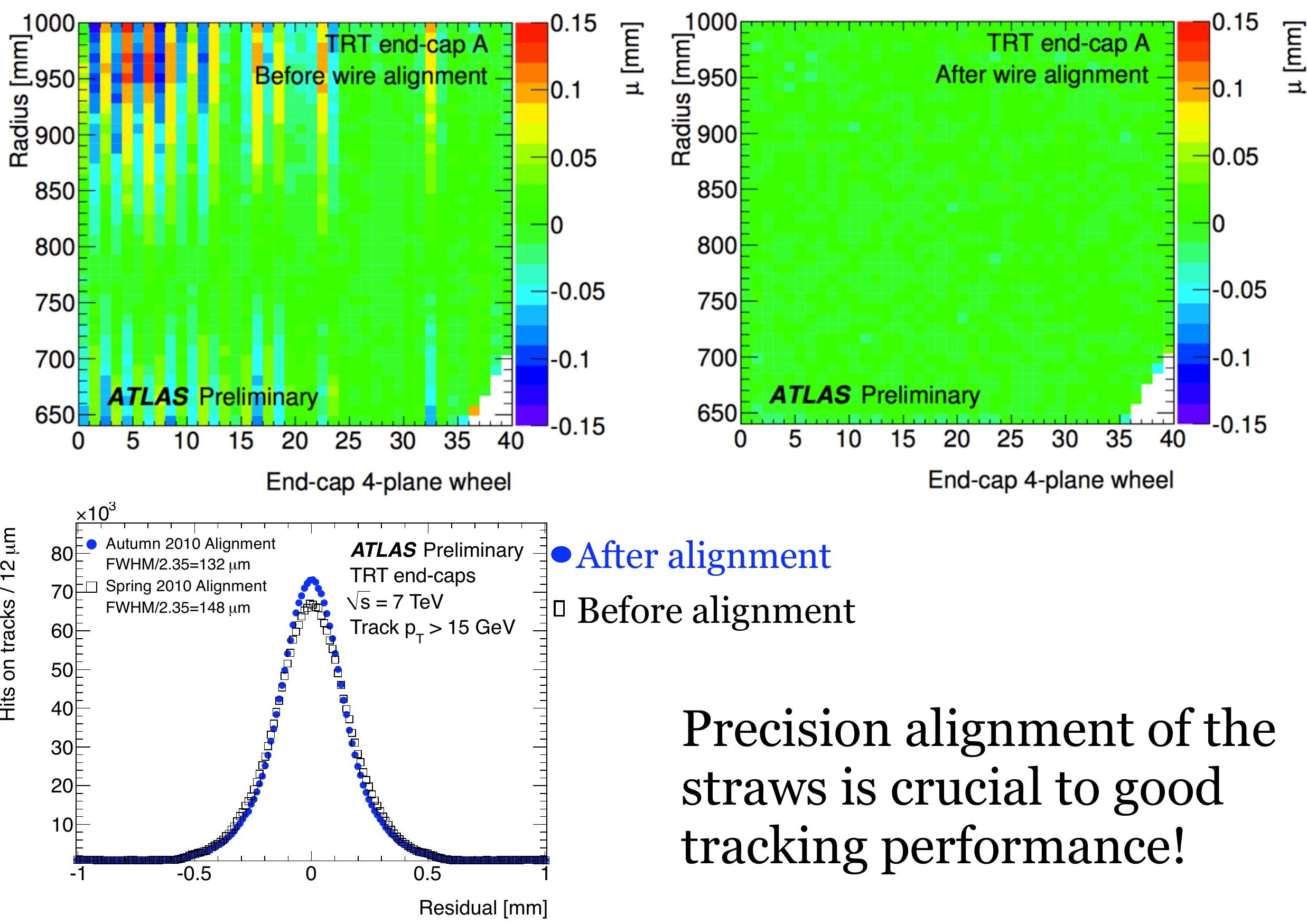


\section{Importance of alignment}

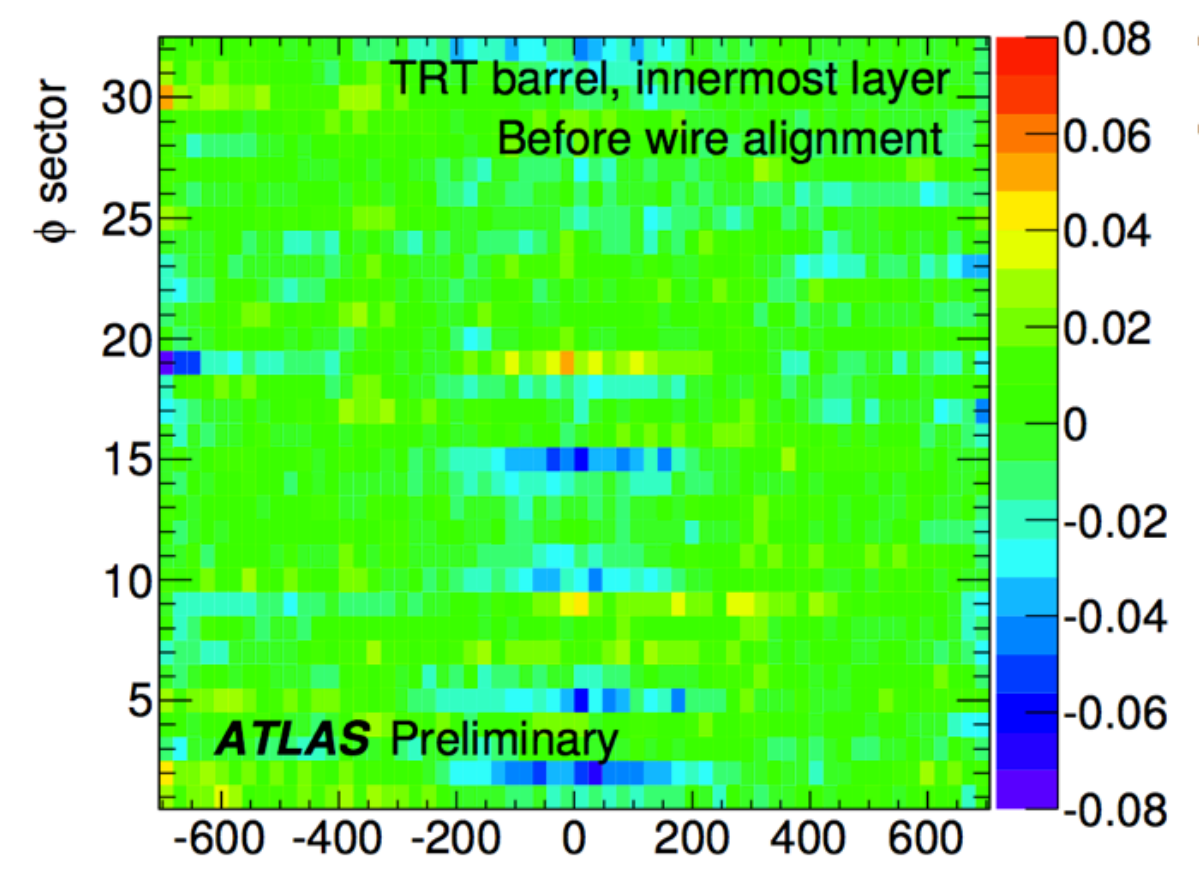

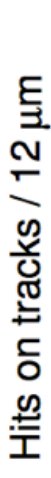

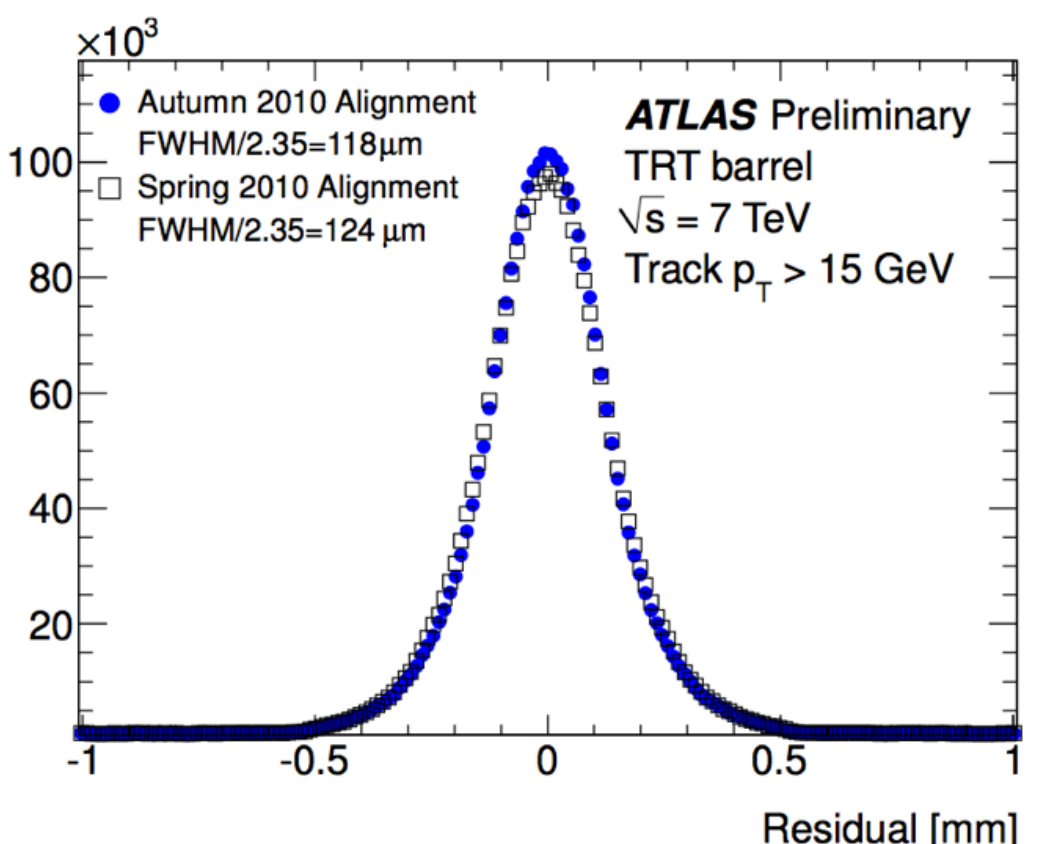

- After alignment

$\checkmark$ Before alignment

Precision alignment also important in the barrel 


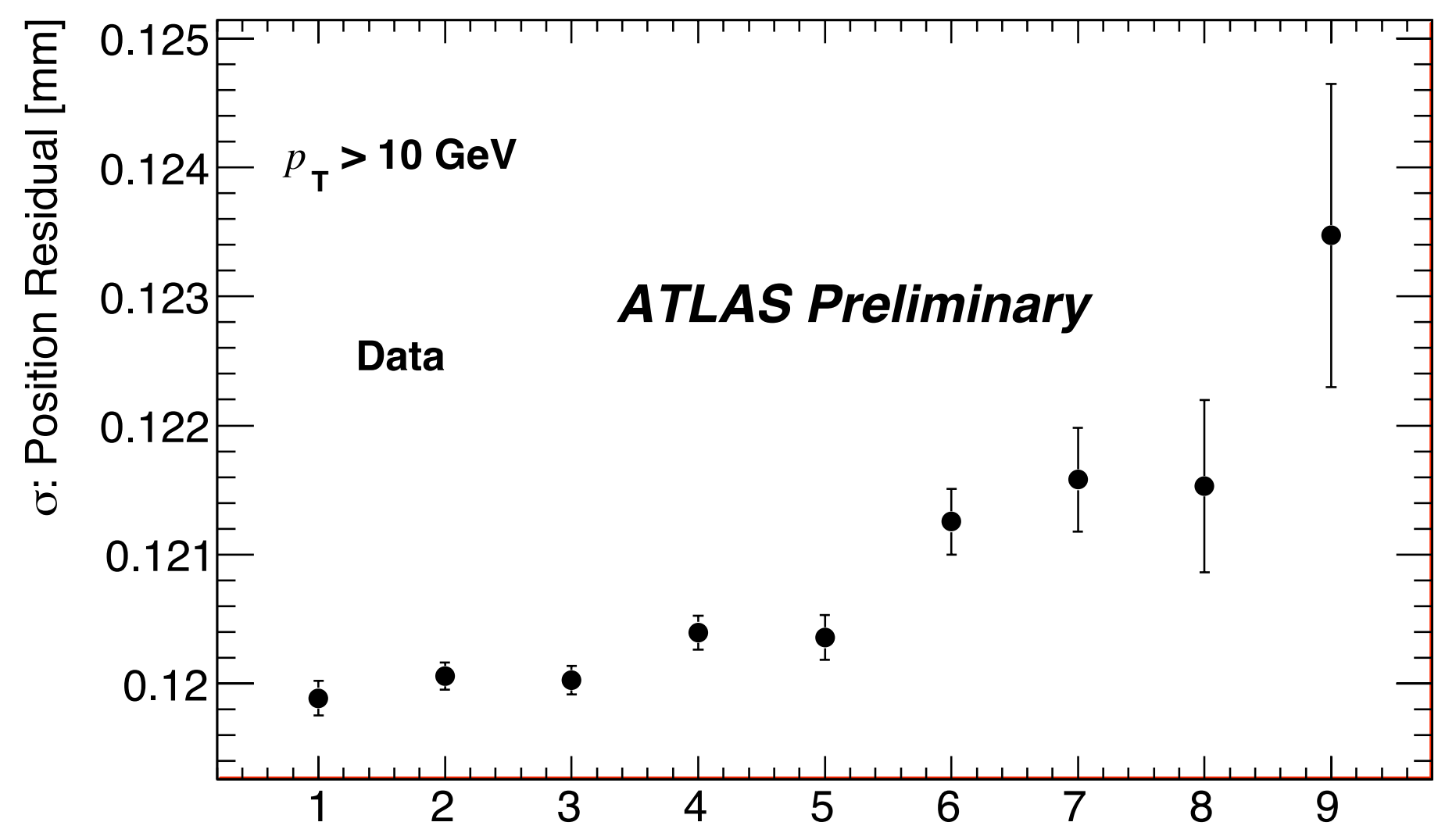

Number of primary vertices

Position residual width (barrel+endcap) as a function of the number of reconstructed primary vertices found in the event 


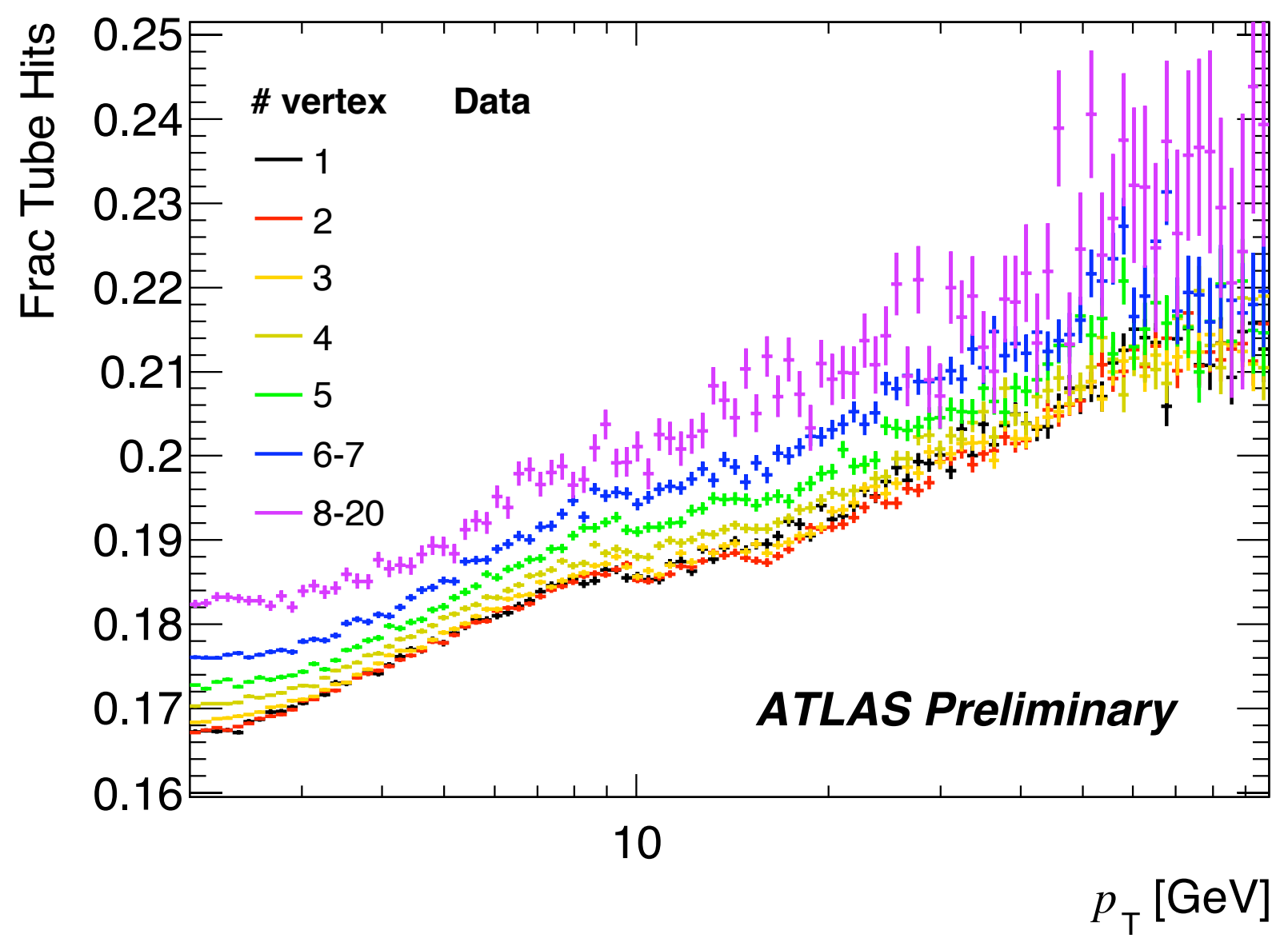

Fraction of TRT hits on track that are labeled as "non-precision hits" by the tracking software, as a function of track pt, shown for events with different numbers of reconstructed primary vertices 

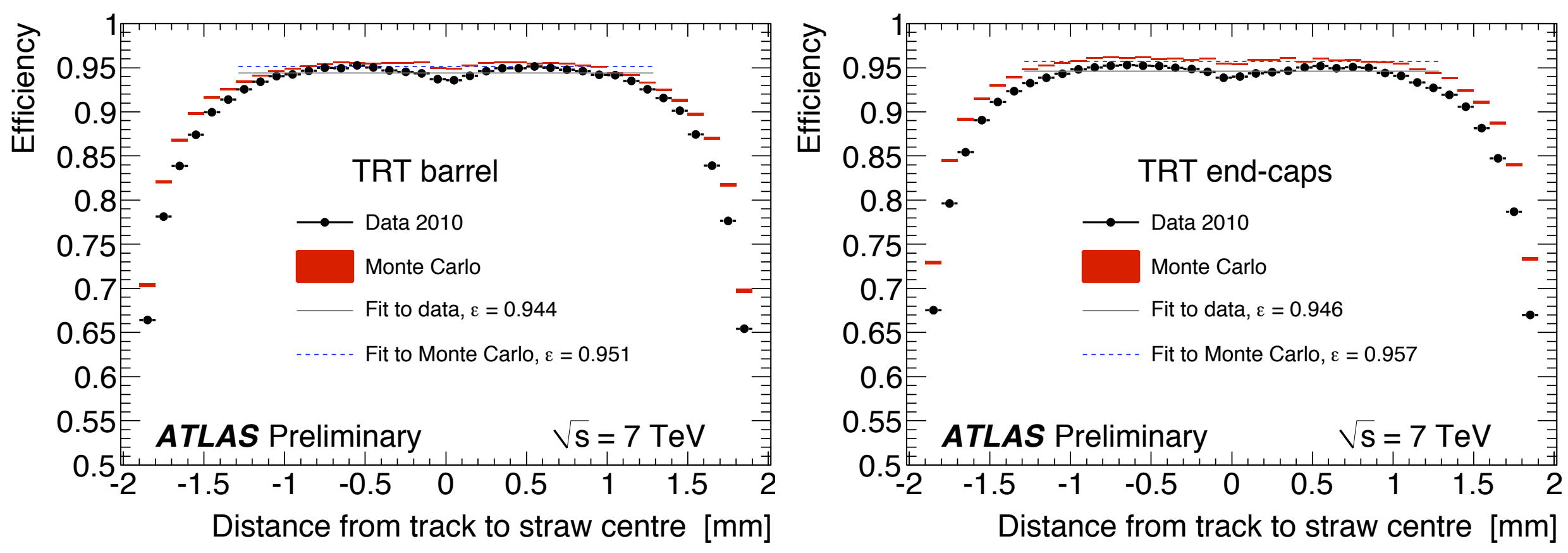

\section{Track efficiency for hits on track, excluding $2 \%$ known non-functioning straws}




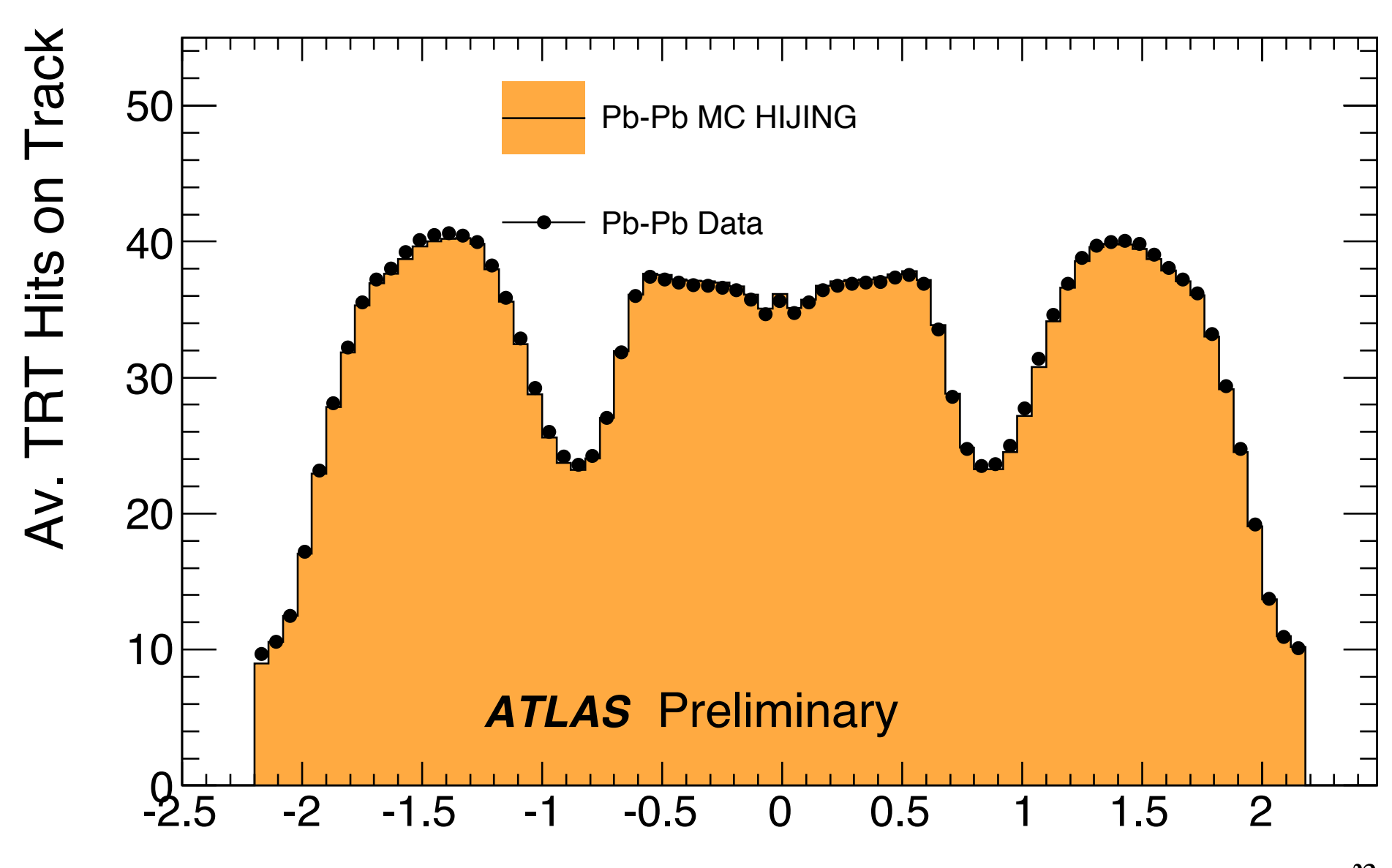

Studies indicate that TRT can contribute even in heavy ion collisions where occupancy can reach $>90 \%$ 
- High level occupancy not yet affected significantly due to pileup, however at some point this will no longer be the case!

- What about $25 \mathrm{~ns}$ bunch spacing of LHC?

- Recall: HL bits read out in OR of 3 windows 25 ns windows. Can use only middle window (keeps $>90 \%$ of transition radiation).

- ToT for PID becomes harder to use, too

- PID in heavy ion collisions?

- Studies underway

\section{Very active area of study!}


- The TRT is performing quite well and contributing significantly to tracking and to ATLAS PID

- Precision alignment and calibration are important for optimal performance

- 50 ns bunch spacing is not much of an issue

- Potential 25 ns bunch spacing next year will be doable as well

- No major degradation yet in terms of tracking/ PID performance at high pileup 
- Rate/straw up to $20 \mathrm{MHz}, 48$ ns max. drift time - Amplifier/shaper with ion tail cancellation and baseline restoration

- Two discriminators for each channel

- 200 - 300 eV (15\% MIP) tracking threshold

- $\sim 7 \mathrm{keV}$ TR threshold

- Digital pipeline, $6 \mu$ s deep

- Tracking bit stored every $3.12 \mathrm{~ns}$

- TR bit stored every $25 \mathrm{~ns}$ 
Counting Rate per wire Ionization Current Density

Ionization Current per wire

Power dissipated by ionization current per straw

Total ionization current in detector volume

Total dissipated energy in the detector volume from ionizing particles

Charge collected over 10 years of LHC operation

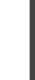

$20 \mathrm{MHz}$

$0.15 \mu \mathrm{A} / \mathrm{cm}$

$10 \mu \mathrm{A}$

$15 \mathrm{~mW}$

Neutrons $10^{6} \mathrm{n} / \mathrm{cm}^{2} \mathrm{sec}$

Particle Flux at $1 \mathrm{~m}$ from IP

\begin{tabular}{|c|c|}
\hline Charged & $10^{5}$ hadrons $/ \mathrm{cm}^{2} \mathrm{sec}$ \\
\hline Photons & $10^{6}$ photons $/ \mathrm{cm}^{2} \mathrm{sec}$ \\
\hline Neutrons & $10^{6} \mathrm{n} / \mathrm{cm}^{2} \mathrm{sec}$ \\
\hline
\end{tabular}

Total Radiation Dose after 10 years

\begin{tabular}{|c|c|} 
Total Radiation Dose after 10 years \\
\hline Neutrons & $10^{14} \mathrm{n} / \mathrm{cm}^{2}$ \\
\hline Charged Particles & $10 \mathrm{MRad}$ \\
\hline
\end{tabular}

$5 \mathrm{~kW}$

3 A

$5 \mathrm{~kW}$

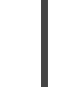

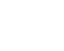

$10 \mathrm{C} / \mathrm{cm}$

